\title{
Novel rapid identification of Severe Acute Respiratory Syndrome Coronavirus 2 (SARS-CoV-2) by real-time RT-PCR using BD Max Open System in Taiwan
}

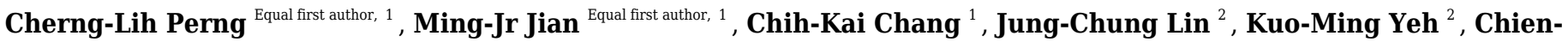
Wen Chen ${ }^{3}$, Sheng-Kang Chiu ${ }^{2}$, Hsing-Yi Chung ${ }^{1}$, Yi-Hui Wang ${ }^{1}$, Shu-Jung Liao ${ }^{1}$, Shih-Yi Li ${ }^{1}$, Shan-Shan Hsieh ${ }^{1}$, Shih-Hung Tsai ${ }^{4}$, Feng-Yee Chang ${ }^{\text {Corresp., }}{ }^{2}$, Hung-Sheng Shang ${ }^{\text {Corresp. } 1}$

${ }^{1}$ Division of Clinical Pathology, Department of Pathology, Tri-Service General Hospital, National Defense Medical Center, Taipei, Taiwan, ROC

2 Division of Infectious Diseases and Tropical Medicine, Department of Medicine, Tri-Service General Hospital, National Defense Medical Center, Taipei, Taiwan, ROC

3 Division of Pulmonary and Critical Care Medicine, Department of Medicine, Tri-Service General Hospital, National Defense Medical Center, Taipei, Taiwan, ROC

${ }^{4}$ Department of Emergency Medicine, Tri-Service General Hospital, National Defense Medical Center, Taipei, Taiwan, ROC

Corresponding Authors: Feng-Yee Chang, Hung-Sheng Shang

Email address: fychang@mail.ndmctsgh.edu.tw, iamkeith001@gmail.com

Coronavirus disease 2019 (COVID-19) has become a worldwide pandemic. By April 7, 2020, approximately $1,279,722$ confirmed cases were reported worldwide including those in Asia, European Region, African Region, and Region of the Americas. Rapid and accurate detection of Severe Acute Respiratory Distress Syndrome Virus 2 (SARS-CoV-2) is critical for patient care and implementing public health measures to control the spread of infection. In this study, we developed and validated a rapid total nucleic acid extraction method based on real-time RT-PCR for reliable, high-throughput identification of SARSCoV-2 using the BD MAX Platform. For clinical validation, 300 throat swab and 100 sputum clinical samples were examined by both the BD MAX Platform and in-house real-time RTPCR methods, which showed $100 \%$ concordant results. This BD MAX protocol is fully automated and the turnaround time from sample to results is approximately $2.5 \mathrm{~h}$ for 24 samples compared to $4.8 \mathrm{~h}$ by in-house real-time RT-PCR. Our developed BD MAX RT-PCR assay can accurately identify SARS-CoV-2 infection band shorten the turnaround time to increase the effectiveness of control and prevention measures for this emerging infectious disease. 
1 Novel rapid identification of Severe Acute Respiratory Syndrome Coronavirus 2

2 (SARS-CoV-2) by Real-time RT-PCR using BD Max Open System in Taiwan

3 Cherng-Lih Perng, ${ }^{\mathrm{a},}$, Ming-Jr Jian, ${ }^{\mathrm{a},}$, Chih-Kai Chang, ${ }^{\mathrm{a}}$, Jung-Chung Lin ${ }^{\mathrm{b}}$, Kuo-Ming Yeh ${ }^{\mathrm{b}}$, Chien-

4 Wen Chen ${ }^{c}$, Sheng-Kang Chiu ${ }^{b}$, Hsing-Yi Chunga, Yi-Hui Wang ${ }^{a}$, Shu-Jung Liao ${ }^{a}$, Shih-Yi Li ${ }^{a}$,

5 Shan-Shan Hsieh ${ }^{a}$, Shih-Hung Tsaid ${ }^{\text {, Feng-Yee Chang }}{ }^{\text {b\#}}$, Hung-Sheng Shanga\#

6

7 a Division of Clinical Pathology, Department of Pathology, Tri-Service General Hospital,

8 National Defense Medical Center, Taipei, Taiwan, ROC

$9{ }^{\mathrm{b}}$ Division of Infectious Diseases and Tropical Medicine, Department of Medicine, Tri-Service

10 General Hospital, National Defense Medical Center, Taipei, Taiwan, ROC

$11^{c}$ Division of Pulmonary and Critical Care Medicine, Department of Medicine, Tri-Service

12 General Hospital, National Defense Medical Center, Taipei, Taiwan, ROC

$13{ }^{\mathrm{d}}$ Department of Emergency Medicine, Tri-Service General Hospital, National Defense Medical

14 Center, Taipei, Taiwan, ROC

15

$16{ }^{\#}$ Corresponding author, email:

17 Hung-Sheng Shang: iamkeith001@gmail.com

18 Feng-Yee Chang: fychang@ndmctsgh.edu.tw

19

$20 *$ These Authors contributed equally to this study.

21 Running title: SARS-CoV-2 Real-time RT-PCR by BD MAX assay 


\section{Abstract}

23 Coronavirus disease 2019 (COVID-19) has become a worldwide pandemic. By April 7, 2020,

24 approximately 1,279,722 confirmed cases were reported worldwide including those in Asia,

25 European Region, African Region, and Region of the Americas.

26 Rapid and accurate detection of Severe Acute Respiratory Distress Syndrome Virus 2 (SARS-CoV-2)

27 is critical for patient care and implementing public health measures to control the spread of

28 infection. In this study, we developed and validated a rapid total nucleic acid extraction method

29 based on real-time RT-PCR for reliable, high-throughput identification of SARS-CoV-2 using

30 the BD MAX Platform.

31 For clinical validation, 300 throat swab and 100 sputum clinical samples were examined by both

32 the BD MAX Platform and in-house real-time RT-PCR methods, which showed 100\%

33 concordant results. This BD MAX protocol is fully automated and the turnaround time from

34 sample to results is approximately $2.5 \mathrm{~h}$ for 24 samples compared to $4.8 \mathrm{~h}$ by in-house real-time

35 RT-PCR.

36 Our developed BD MAX RT-PCR assay can accurately identify SARS-CoV-2 infection band

37 shorten the turnaround time to increase the effectiveness of control and prevention measures for

38 this emerging infectious disease 


\section{Introduction}

41 On December 31, 2019, a cluster of pneumonia cases of unknown etiology was reported in

42 Wuhan, Hubei Province, China (Chan et al. 2020a). Later, the Chinese Centers for Disease

43 Control and Prevention (China CDC) reported a novel coronavirus as the causative agent of this

44 outbreak, which was phylogenetically classified into a novel sister clade of SARS virus and

45 named as the severe acute respiratory syndrome coronavirus 2 (SARS-CoV-2). The disease

46 caused by this virus has been called as novel coronavirus disease 2019 (COVID-19).

47 COVID-19 is an emerging whole world crisis issue. On March 11, 2020, the COVID-19

48 outbreak was characterized as a pandemic by the World Health Organization. By April 7, 2020,

4972614 fatalities and 1,279,722 laboratory-confirmed cases were reported globally ((CDC) 2020;

50 Ghinai et al. 2020; WHO 2020; Wu \& McGoogan 2020).

51 A robust, sensitive, specific, and high-throughput molecular detection method is urgently needed

52 for SARS-CoV-2 diagnosis. Various methods for detecting SARS-CoV-2 have been reported,

53 including real-time reverse transcription polymerase chain reaction (RT-PCR) and serological

54 testing (Ai et al. 2020; Li et al. 2020b; Yu et al. 2020). Currently, real-time RT-PCR is considered as the gold standard of diagnosis for SARS-CoV-2 because of its high sensitivity; this method can detect SARS-CoV-2 in various samples types, including oropharyngeal swab,

57 sputum, and blood (Wang et al. 2020a; Xie et al. 2020). 
58 The BD MAX System (BD Diagnostic Systems, Franklin Lakes, NJ, USA) is an automated

59 platform on which nucleic acid extraction and real-time RT-PCR are performed on the same

60 instrument. This BD MAX System offers not only FDA-cleared panel assays but also an open

61 system mode for user-developed tests (Hofko et al. 2014; McHugh et al. 2018; Stokes et al.

62 2019; Widen et al. 2014). This study was designed to develop a dual RT-PCR tests for detecting

63 the $E$ and $R d R p$ genes of SARS-CoV-2 directly from clinical samples using the open system

64 mode of the BD MAX instrument, and compare the results to those obtained by the in-house

65 real-time RT-PCR method used in our hospital.

66 Materials and Methods

\section{Clinical specimens}

68 This study was approved by Institutional Review Board, Tri-Service General Hospital

69 (TSGHIRB No.: C202005041), registered on 20 March 2020. Informed consent was obtained

70 from patients who signed permission to participate. Throat swab (COPAN COVID-19 Collection

$71 \&$ Transport Kits with Universal Transport Medium) $(\mathrm{n}=300)$ and sputum $(\mathrm{n}=100)$ samples

72 were collected from patients with highly suspected travel or contact history in northern Taiwan.

73 Positive control was used with patient's diluted positive RNA aliquoted into eppendorf tube

74 stored in $-80^{\circ} \mathrm{C}$ (a range of $\mathrm{Ct}$ value $34 \pm 2$ for each run acceptance). Throat swabs were placed in 
$750.5 \mathrm{~mL}$ phosphate-buffered saline and mixed vigorously with a vortex mixer for $30 \mathrm{~s}$ to release

76 the cells. Sputum was liquefied by adding an equal volume of $2 \% N$-acetyl-L-cysteine in

77 phosphate-buffered saline followed by incubation for $10 \mathrm{~min}$.

\section{In-house SARS-CoV-2 laboratory-developed test (LDT)}

\section{Nucleic acid extraction}

80 Total nucleic acid containing viral RNA was extracted from $0.3 \mathrm{~mL}$ of the throat swab

81 supernatant or liquefied sputum, by using LabTurbo Viral nucleic acid extraction kits on a

82 LabTurbo 48 automatic extractor (Taigen Bioscience Corp., Taipei, Taiwan). RNA was eluted

83 with $60 \mu \mathrm{L}$ of RNase-free water.

\section{Real-time one-step RT-PCR}

85 The primer and probe sequences of the two target genes ( $E$ gene as the first-line screening target,

86 followed by confirmatory testing with the $R d R p$ gene) has been previously described (Corman et

87 al. 2020) (Table 1). The 10x TCID ${ }_{50}$ Equine arteritis virus (EAV) (DIA-EIC; Diagenode,

Belgium) was added to extraction buffer for internal control of monitoring RT-PCR inhibitors(Ct

89 value $32 \pm 2$ as acceptance level for each assay). All primers and probes were synthesised and

90 provided by Tib-Molbiol (Berlin,Germany). All assays were performed under the same

91 conditions with some modifications. A $20-\mu \mathrm{L}$ reaction was prepared containing $5 \mu \mathrm{L}$ of RNA, 10 
$92 \mu \mathrm{L}$ of $2 \mathrm{X}$ SensiFAST Probe No-ROX One-Step mix (Bioline Reagents Ltd., London, UK), 400

$93 \mathrm{nM}$ of forward and reverse primers, $200 \mathrm{nM}$ of probe, $0.2 \mu \mathrm{L}$ of reverse transcriptase, and $0.4 \mu \mathrm{L}$

94 of RiboSafe RNase inhibitor (Bioline Reagents Ltd., London, UK). Thermal cycling was

95 performed as follows: reverse transcription for $10 \mathrm{~min}$ at $50^{\circ} \mathrm{C}$, followed by $95^{\circ} \mathrm{C}$ for 2 min and

96 then 50 cycles of $95^{\circ} \mathrm{C}$ for $5 \mathrm{~s}$ and $58^{\circ} \mathrm{C}$ for $30 \mathrm{~s}$ on a Rotor-Gene Q real-time PCR machine

97 (Qiagen, Hilden, Germany).

98

99

BD MAX System Procedure

We optimized the BD MAX ExK TNA 3 total nucleic acid Extraction Kit on the BD MAX. The

101 BD MAX uses sample buffer tubes containing $750 \mu \mathrm{L}$ lysis buffer to which the maximal $500 \mu \mathrm{L}$ primary sample can be added manually. We compared the in-housed SARS-CoV-2 real-time RTPCR assay with BD MAX System open mode using the same primers, probe, and RT-PCR reagents to detect the $E$ and $R d R p$ genes of SARS-CoV-2. The RT-PCR master mixture without primers \& probe $(15 \mu \mathrm{L}$ of $2 \mathrm{X}$ SensiFAST Probe LowNo-ROX One-Step mix, $0.3 \mu \mathrm{L}$ of reverse transcriptase, and $0.6 \mu \mathrm{L}$ of RiboSafe RNase inhibitor) was added to the position 3 on $\mathrm{BD}$ cartridge (Fig. 1). The volume of $2.5 \mu \mathrm{L}$ of primers and probe mixture of $E$ gene and $R d R p+\mathrm{IPC}$ gene was added to the position 2 and position 4 . Finally, $12.5 \mu \mathrm{L}$ eluted nucleic acid was added to 
109 position 3 and mix with RT-PCR master mixture. $12.5 \mu \mathrm{L}$ of above mixture was added to position

1102 and mix with $2.5 \mu \mathrm{L} E$ gene primers $(2.4 \mathrm{pmole} / \mu \mathrm{L}) \&$ probe $(1.2 \mathrm{pmole} / \mu \mathrm{L})$. Residual $12.5 \mu \mathrm{L}$

111 mixture was added to position 4 mixing with $2.5 \mu \mathrm{L} R d R p+\mathrm{IPC}$ gene primers $(2.4 \mathrm{pmole} / \mu \mathrm{L}) \&$

112 probe $(1.2 \mathrm{pmole} / \mu \mathrm{L})$. The mixture in position 2 and 4 were transferred to TOP/BOTTOM PCR

113 chamber (Fig. 1). We carried out the entire sample-to-result procedure in the BD MAX PCR

114 Cartridges. Assay precision was determined by testing individual samples divided into five parts

115 and extracted/assayed separately. The LDT(laboratory developed test) SARS-CoV-2 real-time

116 RT-PCR assay was used as the "gold standard" to assess the diagnostic performance of the BD

117 MAX assay. The BD MAX assay hands-on time was estimated as the sum of the times required

118 to complete sample preparation, device loading and cleaning, and result review and reporting.

\section{Results}

120 Turnaround time for detecting SARS-COV-2 on the BD MAX System

121 The procedures used for the BD MAX System included sample preparation, device loading, total

122 nucleic acid extraction, RT-PCR, and results interpretation. The hands-on time and turnaround

123 time between the LDT(laboratory developed test) and BD MAX System were compared (Fig. 2).

124 Use of the BD MAX System improved the turnaround time from $4.8 \mathrm{~h}$ to approximately $2.5 \mathrm{~h}$

125 with 24 samples processed simultaneously including prepare samples,clean and prepare rack, 
126 create worklist prepare MMK (mastermix), while also decreasing hands-on time, reducing

127 exposure risk. The BD MAX System can also provide results for 192-216 samples in $11 \mathrm{~h}$

128 (depending on how many batches), showing improved capacity compared to the LDT (laboratory

129 developed test).

130 Clinical performance of BD MAX System

131 The analytical specificity of SARS-CoV-2 $E$ and $R d R p$ gene detection by real-time RT-PCR as

132 well as the cross-reactivity with other respiratory pathogens were determined previously

133 (Corman et al. 2020). Here, we focused on the clinical performance of detection using the BD

134 MAX System.

135 Reproducibility of BD MAX assay

136 Five replicates of serial dilutions of SARS-CoV-2-positive samples and a negative template

137 control were tested to evaluate the intra- and inter-assay reproducibility of the BD MAX assay

138 (Table 2). The reproducibility of the CT (cycle threshold) value was satisfactory, showing a

139 coefficient of variation of less than $10 \%$.

140 Comparison of sensitivity of BD MAX assay and LDT (laboratory developed test) RT-PCR

141 The empirical sensitivity of the BD MAX assay was determined by evaluating serial dilutions of

142 positive samples and comparing the results to those of the LDT (laboratory developed test) 
143 assay. As shown in Figure 3, diluted specimens were reliably detected by both assays, from the

144 original titer to the $10^{-3}$ titers. BD MAX assay detected four times in eight replicates in $10^{-4}$ titers

145 which showed less sensitivity compared to LDT (laboratory developed test) assay. Here we we

146 used AcroMetrix Coronavirus 2019 (COVID-19) RNA Control (Thermo Fisher Scientific, USA)

147 that that contain N, S, E and Orflab regions of SARS-CoV-2 genome for absolute quantification

148 and studying the limit of detection (LOD). Replicate reactions were done at concentrations

149 around the detection end point. The limit of detection (LOD) from replicate tests was 8.5 copies

150 per reaction for the $E$ gene and $R d R p$ gene in LDT (laboratory developed test) assay, while 13.9

151 copies per reaction for the $E$ gene and $R d R p$ gene in BD MAX assay.

\section{Clinical validation of BD MAX assay}

153 A total of 400 clinical samples were included in this study. Most samples were throat swabs $(\mathrm{n}=$

$154300)$, followed by sputum $(\mathrm{n}=100)$. Among the 400 samples, 28 samples were positive and 272

155 samples were negative for SARS-CoV-2 real-time RT-PCR with the LDT (laboratory developed

156 test) assay and BD MAX System. These 28 positive samples were further confirmed by Taiwan

157 CDC central laboratory. Concordant results were obtained for both assays in SARS-CoV-2

158 detection, showing 100\% agreement (Table 3). The Ct values of the positive specimens for

159 SARS-CoV-2 $(\mathrm{n}=28)$ were highly correlated in the comparison of the LDT (laboratory 
160 developed test) assay and BD MAX System, with Spearman coefficients of 0.96 and 0.91 ,

161 respectively (Fig. 4).

162

163 Discussion

164 This is the first study of the performance of the SARS-CoV-2 detection assay using the BD

165 MAX System. Compared to the in-house results and those from the reference laboratory, the

166 SARS-CoV-2 assay on the BD MAX showed good performance. In this study, we successfully

167 validated a rapid and high-throughput method on the BD MAX platform for accurately and

168 reproducibly identifying SARS-CoV-2 with a greatly reduced turnaround time and fewer hand-

169 on preparation steps including preparing read-to-use tubes(e.g.100 Rx without reverse

170 transcriptase stored in $\left.-80^{\circ} \mathrm{C}\right)$.

171 Several studies have reported that real-time RT-PCR gives false-negative results in detecting

172 SARS-CoV-2 (Li et al. 2020a; Liu et al. 2020; Winichakoon et al. 2020). Combining real-time

173 RT-PCR testing with other clinical features is necessary to diagnose COVID-19 (Wang et al.

174 2020b).

175 Many detection methods have been used or reported for the diagnosis and/or surveillance of

176 SARS-CoV2 (Chan et al. 2020b; Corman et al. 2020; Wang et al. 2020b; Yang et al. 2020), 
177 among which real-time RT-PCR is the most sensitive. Although this method is routinely used, it

178 requires specialized interpretation and has a long turnaround time. The performance of

179 Molecular BD MAX System for different pathogens has been evaluated previously (Leach et al.

180 2019; Stokes et al. 2019). These studies demonstrate that the BD MAX System is a good

181 diagnostic tool with a rapid turnaround time, enabling appropriate treatment decisions. During

182 the writing of this manuscript, several molecular assays have been developed for detecting and

183 identifying SARS-CoV-2, including the Cobas SARS-CoV-2 test (Roche, Basel, Switzerland)

184 and TaqPath Covid-19 Combo Kit (Thermo Fisher Scientific, Waltham, MA, USA), which have

185 been authorized for use by the US Food and Drug Administration. To overcome the SARS-CoV-

1862 pandemic, more sensitive and robust methods are required.

187 This method had several advantages. First, the use of an automated platform with the same

188 primers, probe, and master mix as used in our manual LDT (laboratory developed test) assay.

189 Second, there was comparable accuracy, sensitivity, and specificity and easy integration into the

190 laboratory workflow. Third, our findings confirm the suitability of the BD MAX system for

191 directly detecting SARS-CoV-2 from clinical specimens.

192 Fourth, the laboratory-developed SARS-CoV-2 BD MAX assay is a dual assay for detecting

193 both $E$ and $R d R p$ gene, allowing for screening and confirming of SARS-CoV-2 infection

194 simultaneously. Fifth, the use of only one plateform test in routine settings for the clinical 
195 diagnosis of emerging infectious agents in various clinical specimens, including sputum and

196 throat swab samples.

\section{Conclusion}

198 In summary, a SARS-CoV-2 real-time PCR molecular test was developed on the BD MAX

199 System. This test showed excellent sensitivity and specificity and can be used to rapidly detect

200 SARS-CoV-2 infection.

201 Our SARS-CoV-2 test is also rapid and high-throughput, providing accurate and reproducible

202 results with a significantly reduced turnaround time and fewer hands-on preparation steps. This

203 method is very easy with less skillful requirements and can be implemented in emergency

204 mediccal laboratories for only short training course.

\section{Acknowledgments}

206 We acknowledge and thank technical personnel of BD Diagnostics, for her technical support.

\section{Grants}

208 This study was supported by Tri-Service General Hospital, Taipei, Taiwan, ROC, Grant

209 Numbers: TSGH-D-109142. The funders had no role in study design, data collection and

210 analysis, decision to publish, or preparation of the manuscript. The authors declare no conflicts

211 of interest. 


\section{References:}

218 Ai JW, Zhang Y, Zhang HC, Xu T, and Zhang WH. 2020. Era of molecular diagnosis for

219 pathogen identification of unexplained pneumonia, lessons to be learned. Emerg

220

Microbes Infect 9:597-600. 10.1080/22221751.2020.1738905

221 Centers for Disease Control and Prevention (CDC) . 2020. Coronavirus Disease 2019 (COVID-

222

19) in the U.S. Available at https://www.cdc.gov/coronavirus/2019-ncov/cases-in-us.html

223

(accessed 2020/04/15.

224 Chan JF-W, Yuan S, Kok K-H, To KK-W, Chu H, Yang J, Xing F, Liu J, Yip CC-Y, Poon RW-

S, Tsoi H-W, Lo SK-F, Chan K-H, Poon VK-M, Chan W-M, Ip JD, Cai J-P, Cheng VC-

228

study of a family cluster. The Lancet 395:514-523. 10.1016/s0140-6736(20)30154-9

229

230

231

C, Chen H, Hui CK-M, and Yuen K-Y. 2020a. A familial cluster of pneumonia

associated with the 2019 novel coronavirus indicating person-to-person transmission: a

Chan JF, Yip CC, To KK, Tang TH, Wong SC, Leung KH, Fung AY, Ng AC, Zou Z, Tsoi HW, Choi GK, Tam AR, Cheng VC, Chan KH, Tsang OT, and Yuen KY. 2020b. Improved molecular diagnosis of COVID-19 by the novel, highly sensitive and specific COVID-19$\mathrm{RdRp} / \mathrm{Hel}$ real-time reverse transcription-polymerase chain reaction assay validated in vitro and with clinical specimens. J Clin Microbiol. 10.1128/JCM.00310-20 
234 Corman VM, Landt O, Kaiser M, Molenkamp R, Meijer A, Chu DKW, Bleicker T, Brünink S,

235 Schneider J, Schmidt ML, Mulders DGJC, Haagmans BL, van der Veer B, van den Brink

236 S, Wijsman L, Goderski G, Romette J-L, Ellis J, Zambon M, Peiris M, Goossens H,

237 Reusken C, Koopmans MPG, and Drosten C. 2020. Detection of 2019 novel coronavirus

238 (2019-nCoV) by real-time RT-PCR. Eurosurveillance 25. 10.2807/1560-

239

7917.Es.2020.25.3.2000045

240 Ghinai I, McPherson TD, Hunter JC, Kirking HL, Christiansen D, Joshi K, Rubin R, Morales-

USA. Lancet. 10.1016/S0140-6736(20)30607-3

248 Hofko M, Mischnik A, Kaase M, Zimmermann S, and Dalpke AH. 2014. Detection of carbapenemases by real-time PCR and melt curve analysis on the BD Max system. J Clin Microbiol 52:1701-1704. 10.1128/JCM.00373-14 
251 Leach L, Russell A, Zhu Y, Chaturvedi S, and Chaturvedi V. 2019. A Rapid and Automated

252

253

254

255

256

257

258

259

260

261

262

263

264

265

266

267

268
Sample-to-Result Candida auris Real-Time PCR Assay for High-Throughput Testing of

Surveillance Samples with the BD Max Open System. J Clin Microbiol 57.

10.1128/JCM.00630-19

Li D, Wang D, Dong J, Wang N, Huang H, Xu H, and Xia C. 2020a. False-Negative Results of Real-Time Reverse-Transcriptase Polymerase Chain Reaction for Severe Acute Respiratory Syndrome Coronavirus 2: Role of Deep-Learning-Based CT Diagnosis and Insights from Two Cases. Korean J Radiol. 10.3348/kjr.2020.0146

Li Z, Yi Y, Luo X, Xiong N, Liu Y, Li S, Sun R, Wang Y, Hu B, Chen W, Zhang Y, Wang J, Huang B, Lin Y, Yang J, Cai W, Wang X, Cheng J, Chen Z, Sun K, Pan W, Zhan Z, Chen L, and Ye F. 2020b. Development and Clinical Application of A Rapid IgM-IgG Combined Antibody Test for SARS-CoV-2 Infection Diagnosis. J Med Virol. 10.1002/jmv.25727

Liu R, Han H, Liu F, Lv Z, Wu K, Liu Y, Feng Y, and Zhu C. 2020. Positive rate of RT-PCR detection of SARS-CoV-2 infection in 4880 cases from one hospital in Wuhan, China, from Jan to Feb 2020. Clin Chim Acta 505:172-175. 10.1016/j.cca.2020.03.009

McHugh MP, Guerendiain D, Hardie A, Kenicer J, MacKenzie L, and Templeton KE. 2018. Detection of Norovirus by BD MAX, Xpert((R)) Norovirus, and xTAG((R)) 
Stokes W, Simner PJ, Mortensen J, Oethinger M, Stellrecht K, Lockamy E, Lay T, Bouchy P, and Pillai DR. 2019. Multicenter Clinical Validation of the Molecular BD Max Enteric Viral Panel for Detection of Enteric Pathogens. J Clin Microbiol 57. 10.1128/JCM.00306-19

275

276

World Health Organization (WHO). 2020. Coronavirus disease 2019 (COVID-19) Situation

$$
\text { Report - 78. WHO. }
$$

Wang W, Xu Y, Gao R, Lu R, Han K, Wu G, and Tan W. 2020a. Detection of SARS-CoV-2 in Different Types of Clinical Specimens. JAMA. 10.1001/jama.2020.3786

Wang Y, Kang H, Liu X, and Tong Z. 2020b. Combination of RT-qPCR testing and clinical features for diagnosis of COVID-19 facilitates management of SARS-CoV-2 outbreak. $J$ Med Virol. 10.1002/jmv.25721

Widen R, Healer V, and Silbert S. 2014. Laboratory evaluation of the BD MAX MRSA assay. $J$ Clin Microbiol 52:2686-2688. 10.1128/JCM.00237-14

Winichakoon P, Chaiwarith R, Liwsrisakun C, Salee P, Goonna A, Limsukon A, and Kaewpoowat Q. 2020. Negative Nasopharyngeal and Oropharyngeal Swab Does Not Rule Out COVID-19. J Clin Microbiol. 10.1128/JCM.00297-20 
287 Wu Z, and McGoogan JM. 2020. Characteristics of and Important Lessons From the Coronavirus

Xie C, Jiang L, Huang G, Pu H, Gong B, Lin H, Ma S, Chen X, Long B, Si G, Yu H, Jiang L, coronavirus detection by nucleic acid amplification tests. Int J Infect Dis. 10.1016/j.ijid.2020.02.050 transcription RT-LAMP method. medRxiv:2020.2003.2002.20030130. $10.1101 / 2020.03 .02 .20030130$ infections by a novel coronavirus responsible for a pneumonia outbreak originating in 
306 Figure legends

307 Figure 1. Experimental design detecting SARS-COV-2 on the BD MAX System

308 Figure 2. Hands-on time and TAT (turn-around time) comparison between in-house LDT

309 (laboratory developed test) and BD MAX System (A)In house LDT (laboratory developed

310 test) assay (B) BD MAX assay

311 Figure 3. Analytic sensitivity of LDT (laboratory developed test) and BD MAX System

312 (A)In house LDT (laboratory developed test) assay (B) BD MAX assay

313 Figure 4. Correlation of $\mathrm{Ct}$ values of clinically positive specimens by LDT(laboratory

314 developed test) and BD Max SARS-Cov2 assays. (A) $E$ gene for SARS-Cov2, Spearman

315 coefficient of 0.96 (B) $R d R p$ gene for SARS-Cov2, Spearman coefficient of 0.91

316

317

318 


\section{Table 1 (on next page)}

primers and probe used in this sutdy

Table 1. Primer and probe sequences used in this study 
1 Table 1. Primer and probe sequences used in this study

Primers and probe sequences used for real-time RT-PCR for detecting SARS-CoV-2

\begin{tabular}{|c|c|c|c|}
\hline Target gene & Primer name & Sequence $\left(5^{\prime} \rightarrow 3^{\prime}\right)$ & Reference \\
\hline \multirow{3}{*}{$R d R P(\mathrm{ORF} 1 \mathrm{ab})$} & RdRP_SARSr-F2 & GTGARATGGTCATGTGTGGCGG & \multirow{6}{*}{ Corman et al. 2020} \\
\hline & RdRP_SARSr-R2 & CAAAATGTTAAA $\underline{A} A C A C T A T T A G C A T A$ & \\
\hline & RdRP_SARSr-P2 & FAM-CAGGTGGAACCTCATCAGGAGATGC-BBQ & \\
\hline \multirow{3}{*}{$E$} & E_Sarbeco_F1 & ACAGGTACGTTAATAGTTAATAGCGT & \\
\hline & E_Sarbeco_R2 & ATATTGCAGCAGTACGCACACA & \\
\hline & E_Sarbeco_P1 & FAM-ACACTAGCCATCCTTACTGCGCTTCG-BBQ & \\
\hline Equine arteritis virus & EAV-IPC-F & CATCTCTTGCTTTGCTCCTT & \multirow{3}{*}{$\begin{array}{c}\text { GenBank } \\
\text { EU586274 }\end{array}$} \\
\hline$(\mathrm{EAV})$ & EAV-IPC-R & AGCCGCACCTTCACATTGAT & \\
\hline IPC & EAV-IPC-F & HEX-CTGACAGCGCTTCTGGTTTCATCAGCT-BHQ & \\
\hline
\end{tabular}

3 Modified the degenerated sequence to fit the Wuhan strain at position 3 from $\mathrm{R}$ to $\mathrm{A}$ and position 12 from $\mathrm{S}$ to $\mathrm{A}$ changes marked with 4 underline. 
Table 2 (on next page)

showing the relative reproducibility of BD MAX system

Table 2 Reproducibility of BD MAX assay for SARS-CoV-2 
1 Table 2 Reproducibility of BD MAX assay for SARS-CoV-2

\begin{tabular}{|c|c|c|c|c|}
\hline \multirow[b]{2}{*}{ SARS-CoV-2 } & \multicolumn{2}{|r|}{ Inter-run } & \multicolumn{2}{|r|}{ Intra-run } \\
\hline & $\begin{array}{l}\text { No. of positive } \\
\text { replicates }\end{array}$ & $\begin{array}{c}\text { Mean } C_{T} \pm \mathrm{SD} \\
\text { (\% coefficient of variation) }\end{array}$ & $\begin{array}{l}\text { No. of positive } \\
\text { replicates }\end{array}$ & $\begin{array}{c}\text { Mean } C_{T} \pm \mathrm{SD} \\
\text { (\% coefficient of variation })\end{array}$ \\
\hline \multicolumn{5}{|l|}{$E$ gene } \\
\hline+++ & 5 & $15.24 \pm 0.95(6.22)$ & 5 & $16.80 \pm 0.95(5.65)$ \\
\hline++ & 5 & $25.06 \pm 0.59(2.35)$ & 5 & $25.34 \pm 0.58(2.29)$ \\
\hline+ & 5 & $34.68 \pm 0.56(1.62)$ & 5 & $35.34 \pm 0.61(1.72)$ \\
\hline \multicolumn{5}{|c|}{$R d R p$ gene } \\
\hline+++ & 5 & $17.04 \pm 1.12(6.58)$ & 5 & $17.26 \pm 1.49(8.65)$ \\
\hline++ & 5 & $26.03 \pm 0.82(3.11)$ & 5 & $26.92 \pm 0.74(2.75)$ \\
\hline+ & 5 & $36.74 \pm 0.41(1.12)$ & 5 & $37.20 \pm 0.43(1.16)$ \\
\hline
\end{tabular}




\section{Table 3(on next page)}

the relative correlation performance between LDT method and BD MAX system

Table. 3 Comparison of the clinical performance of in-house LDT (laboratory developed test) real-time RT-PCR and BD MAX System for SARS-CoV-2 
1 Table. 3 Comparison of the clinical performance of in-house LDT (laboratory developed test) real-time 2 RT-PCR and BD MAX System for SARS-CoV-2

3

4

\begin{tabular}{cccc}
\cline { 2 - 4 } & & \multicolumn{2}{c}{ BD MAX assay } \\
\cline { 2 - 4 } & SARS-CoV-2 & Positive & Negative \\
\hline LDT real-time & Positive & 28 & 0 \\
RT-PCR & Negative & 0 & 372 \\
\hline
\end{tabular}

5

6 Positive: both $E$ gene and $R d R p$ gene were detected; Negative: neither $E$ gene nor $R d R p$ gene were detected

7 SARS-CoV-2: Severe Acute Respiratory Syndrome Coronavirus 2

8

9 
Figure 1

the experimental design in detecing SARS-COV-2 on the BD MAX platform

Figure 1. Experimental design detecting SARS-COV-2 on the BD MAX System

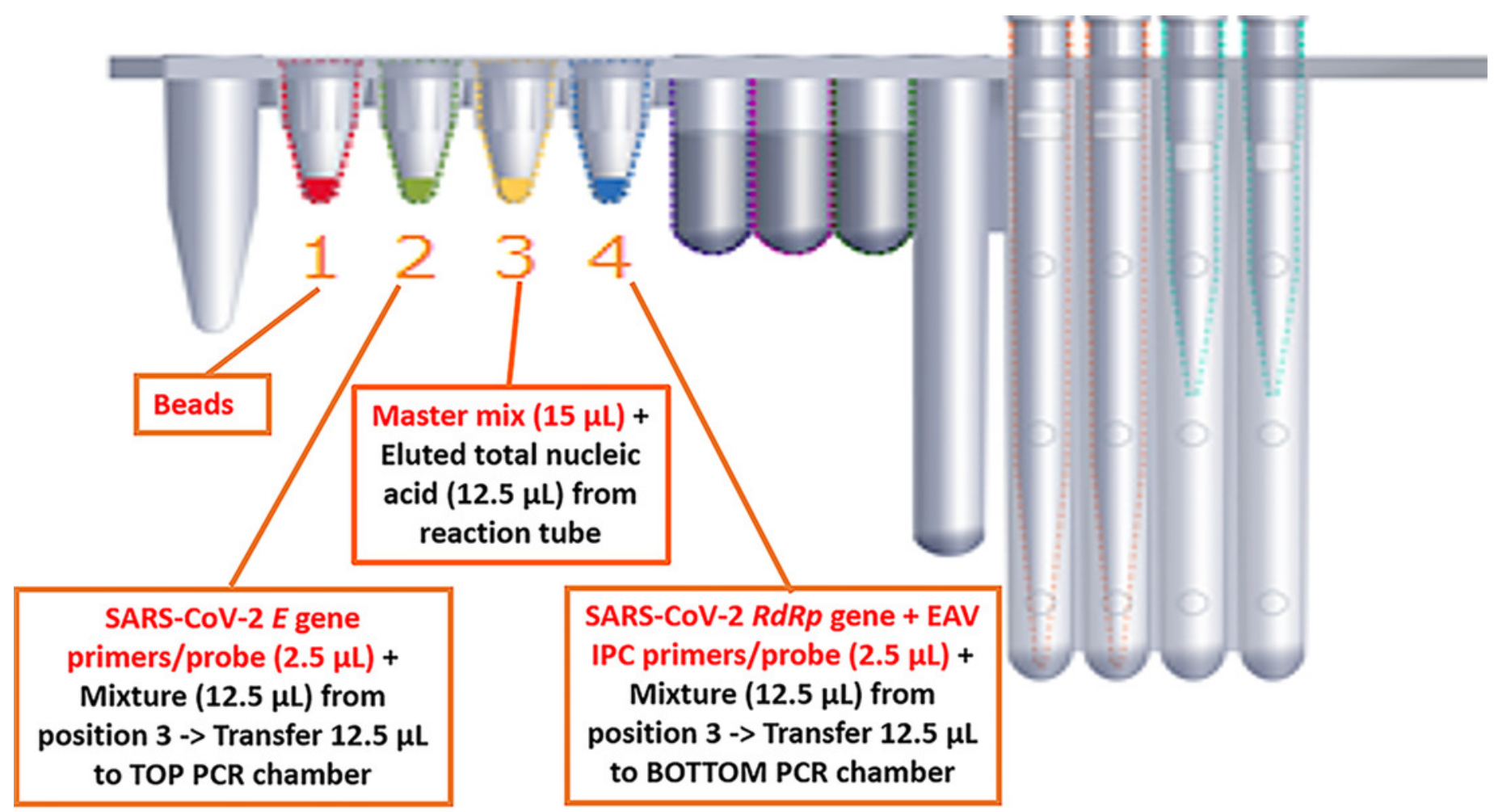


Figure 2

the relative Hands-on time and turn-around time between in-house LDT and BD MAX System

Figure 2. Hands-on time and TAT (turn-around time) comparison between in-house LDT (laboratory developed test) and BD MAX System (A)In house LDT (laboratory developed test) assay (B) BD MAX assay

(A)
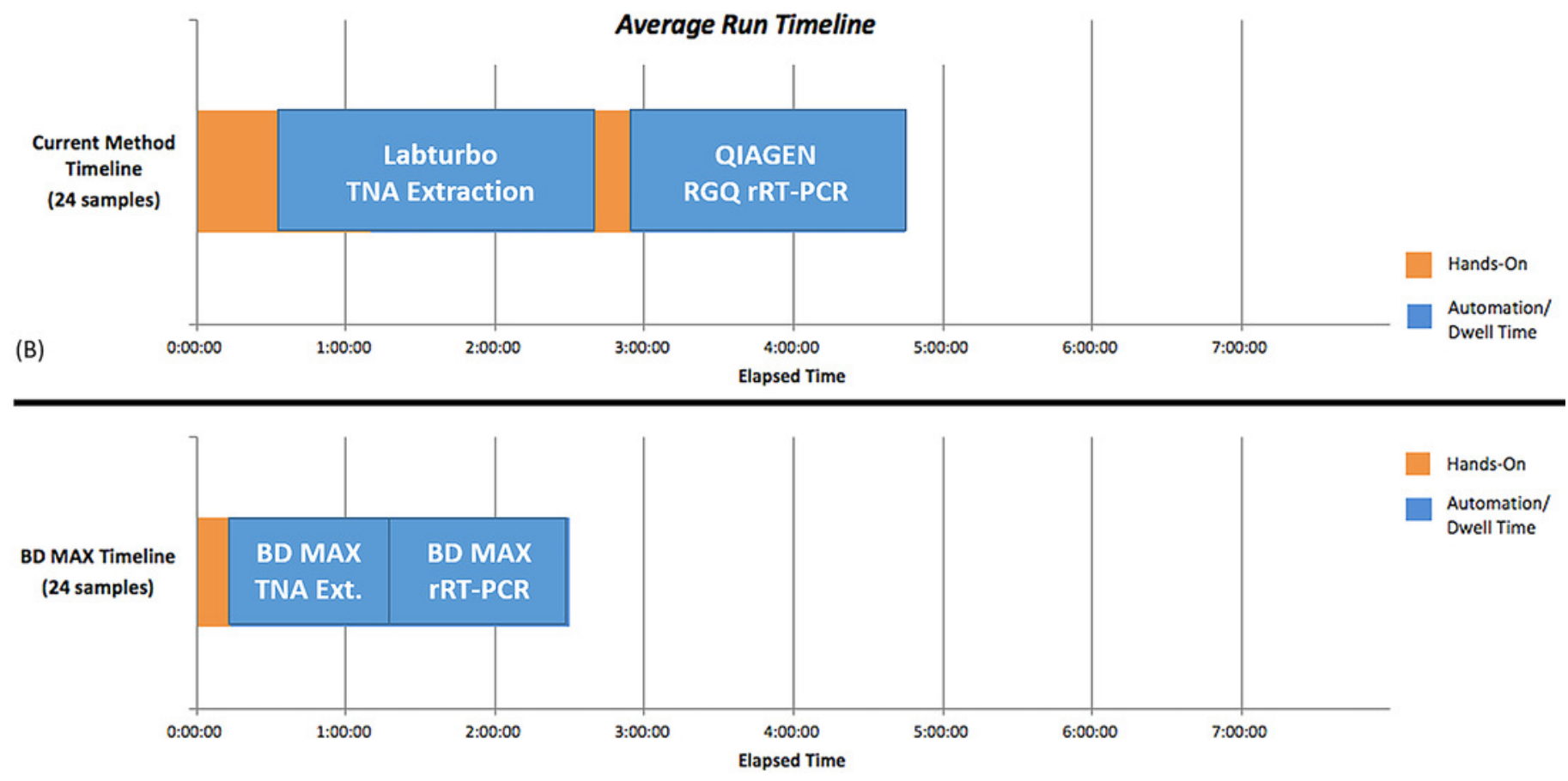
Figure 3

Comparison the relative sensitivity of LDT and BD MAX System

Figure 3. Analytic sensitivity of LDT (laboratory developed test) and BD MAX System (A)In house LDT (laboratory developed test) assay (B) BD MAX assay

(A)

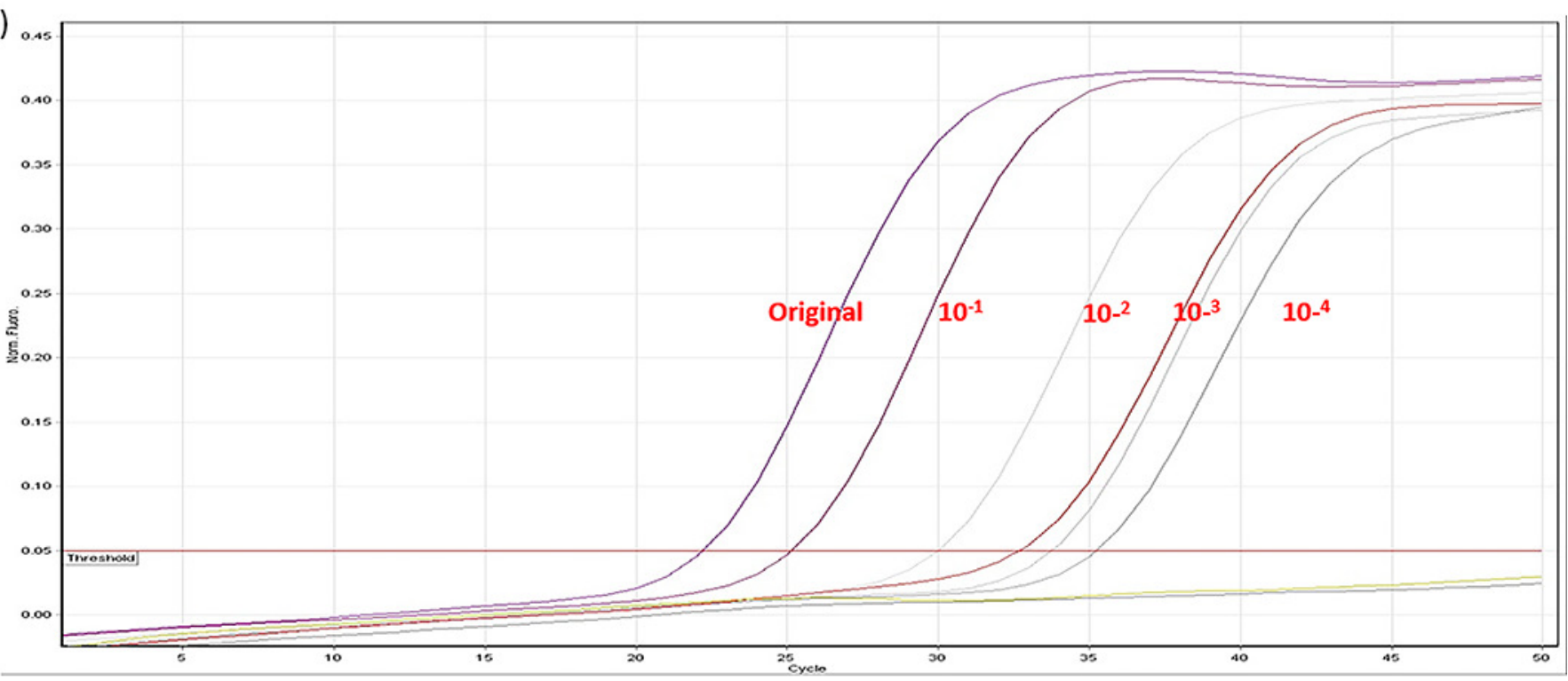

(B)

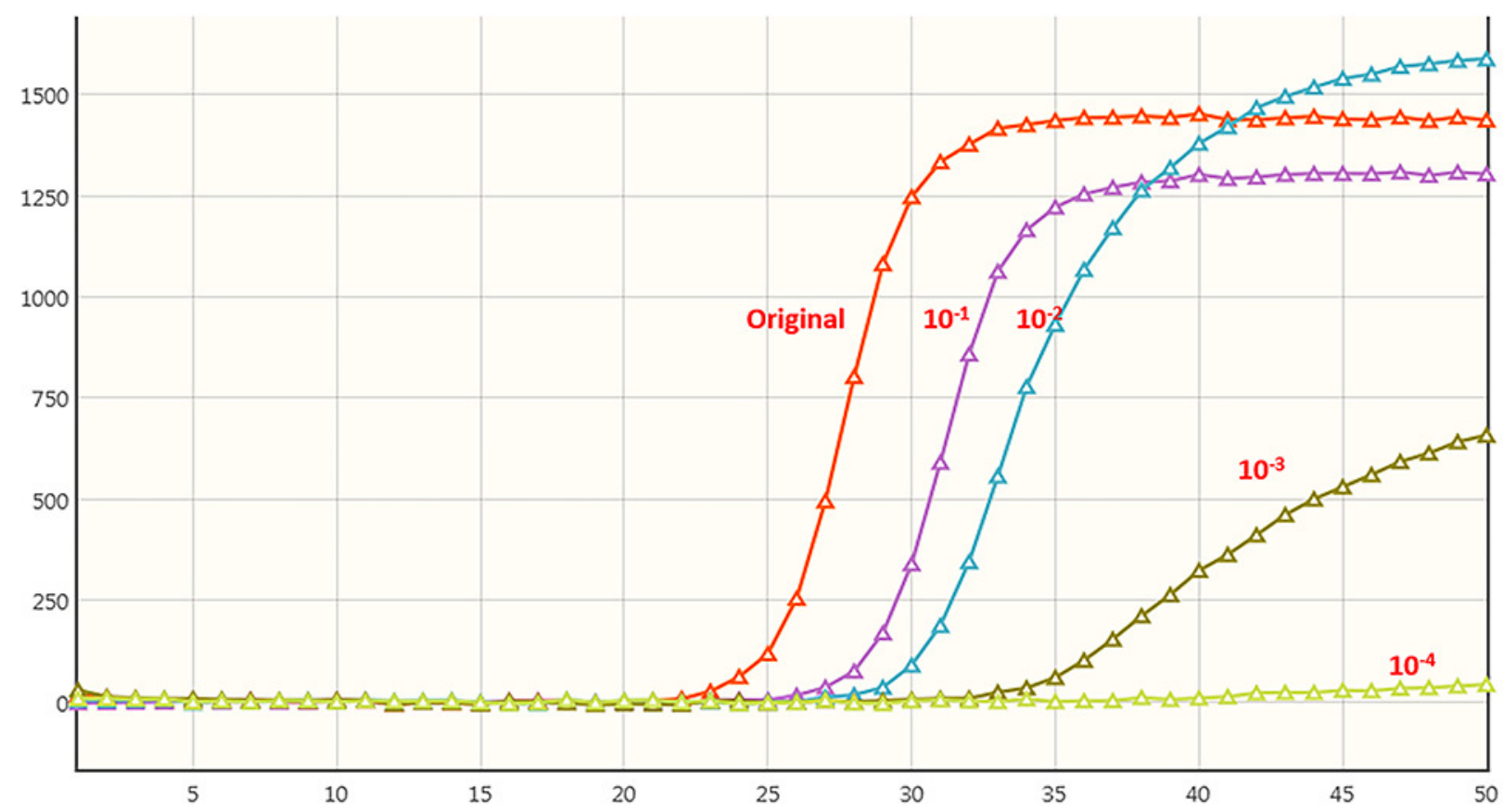


Figure 4

the relative correlation results between LDT and BD MAX System

Figure 4. Correlation of Ct values of clinically positive specimens by

LDT(laboratory developed test) and BD Max SARS-Cov2 assays. (A) E gene for

SARS-Cov2, Spearman coefficient of 0.96 (B) RdRp gene for SARS-Cov2, Spearman coefficient of 0.91

(A)

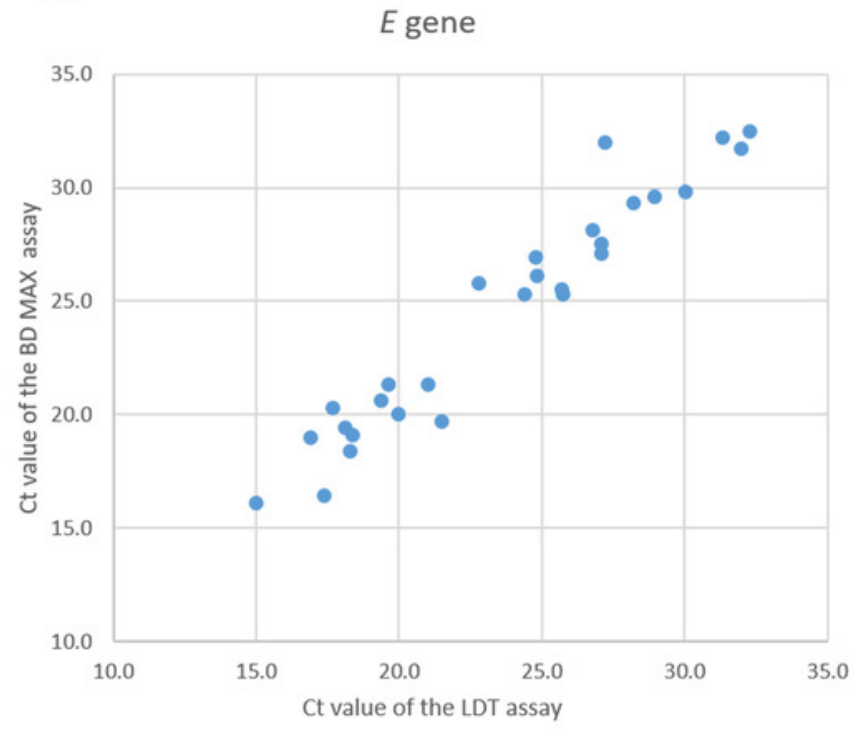

(B)

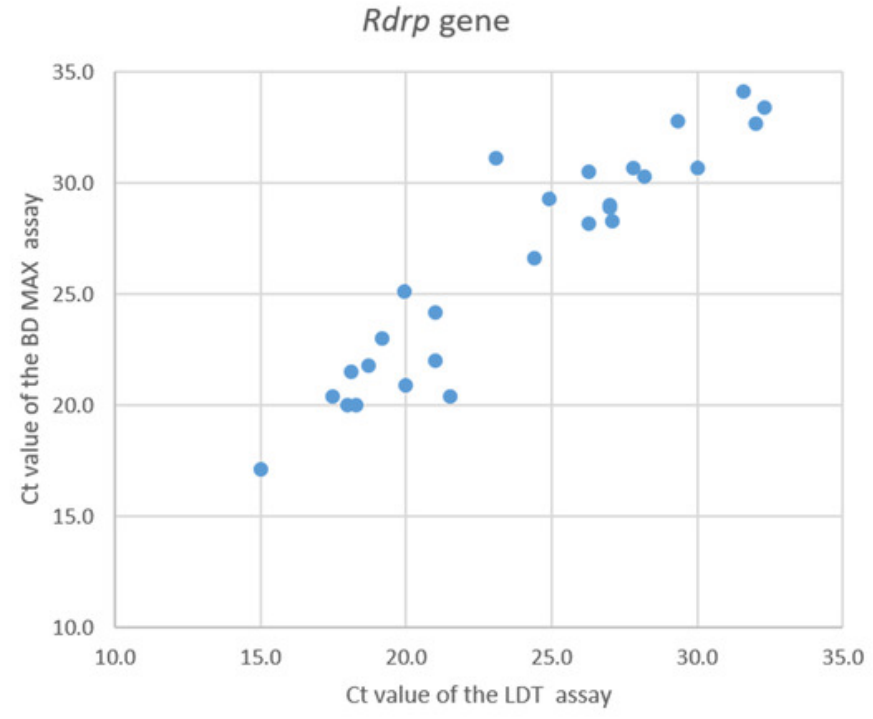

